\title{
Regional Economic Convergence and Spatial Spillovers in Turkey
}

\author{
Ahmet Kındap ${ }^{\circledR}$ and Tayyar Doğan
}

\begin{abstract}
Using sigma and beta convergence methods, this study tests economic convergence in Turkish NUTS-2 regions between 2004-2011. The findings of sigma convergence analysis show that the interregional income gap decreases during economic recession periods and increases during economic expansion periods. The beta convergence results obtained by the cross-sectional and panel estimations indicate the existence of absolute convergence. In addition, spatial data analysis provides strong evidence for the existence of spatial autocorrelation in regional income distribution.
\end{abstract}

Key words: Regional Disparity, Convergence, Spatial Autocorrelation, Spatial Econometrics, Spatial Spillovers

JEL Classifications: R11, R12

\section{INTRODUCTION}

Turkey suffers from large and persistent development disparities between western and eastern regions. While western regions attract most of the economic activities and investment, eastern regions struggle with severe economic and social problems such as inadequate investment and services, unemployment and poverty. This economic division triggers migration from East to West and results in high unemployment and congestion in metropolitan areas. Thus, reducing these development disparities and ensuring coherent development in the entire country have been among the main concerns of the policy makers. Turkey has developed a set of regional development tools and mechanisms including priority regions for development, comprehensive regional development projects/plans, state aids and large public investment projects. However, these traditional top-down and state-oriented regional policies were far from reducing the spatial economic inequality. Most empirical studies analyzing regional economic convergence in the pre-2001 period indicate lack of significant convergence (Atalik, 1990; Filiztekin, 1998; Berber et al., 2000; Gezici and Hewings, 2002; Aldan and Gaygisiz, 2006).

The authors observation is that in the 2000s with the process of harmonization efforts with European Union legislation, Turkey went through a transformation in its regional policy adopting a more bottom-up and participatory approach in line with the contemporary regional development literature. Main pillars of this new policy agenda are: (i) adaptation of a new regional classification and statistical system and (ii) the establishment of Development Agencies (DAs), which brings about the institutionalization of regional level governance and creation of a fund for regional development.

\footnotetext{
${ }^{\circledR}$ Ahmet KINDAP, Urban Planner, Republic of Turkey Ministry of Industry and Technology, Ankara, Turkey, (email: akindap@gmail.com), Tel: +90 5053003058.

Tayyar DOĞAN, PwC, Senior Consultant, Ankara, Turkey (email: tayyardogan84@ gmail.com), Tel: +90 535641 0359.
} 
The latest regional statistics show that regional development disparities between eastern and western regions are still large (Figure 1.1), but they also indicate some preliminary signals for convergence achieved so far. While gross value added (GVA) per capita level of the most developed region is nearly 4.29 times that of the least developed region in 2004, the ratio decreased to 3.94 in 2011. As seen in the Figure 1.2, poorer regions had better growth performance during 2004-2011 period for which the GVA per capita data are available at regional level.

Figure 1.1 GVA per capita by NUTS 2 Regions, 2011

Source: TURKSTAT (2014)

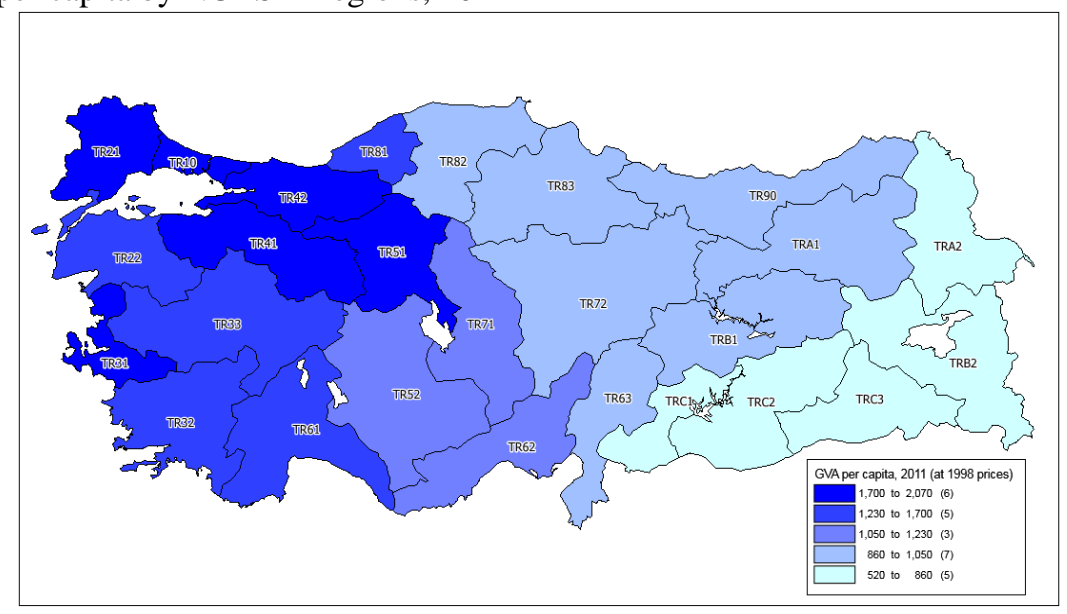

Figure 1.2 Annual GVA per capita Growth Rate by NUTS 2 Regions, 2004-2011

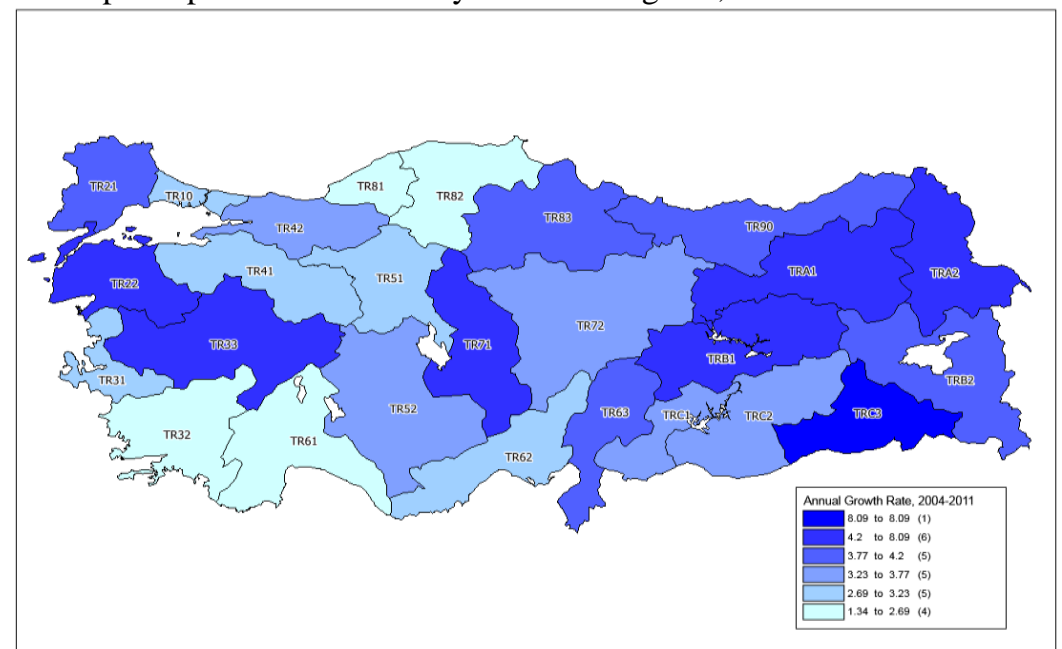

Source: TURKSTAT (2014)

Figure 1.3 displays relative positions of NUTS II regions with reference to the country average in 2004 and 2011, and points out that poorer regions converge towards the country average. When we look at the absolute values, we see that in the 2004-2011 period, per capita income has increased in all regions (Figure 1.2). Thus, relative convergence in Figure 3 happened because regions with the relatively low GVA per capita had better growth performance and made relatively more contribution to national growth than they did in the past.

Although general overview of the latest statistics provides some evidence of regional convergence, reaching an accurate conclusion requires further analysis. Thus, this study mainly aims at testing whether the regions of Turkey converge or diverge by using contemporary methods in the literature and answering the questions of whether regional disparities decreased 
between 2004 and 2011. Secondly, Figure 1.1 and 1.2 visually show that regions that are close to one another have similar levels of GVA per capita levels and growth rates, the study will test whether geographical proximity has a statistically significant effect on the growth rates of the regions. Finally, the effect of the 2008 financial crisis on the convergence will be assessed to see if the regional convergence has a pro-cyclical character as widely seen in the literature

Figure 1.3 GVA per capita by NUTS II Regions (Turkey =100)

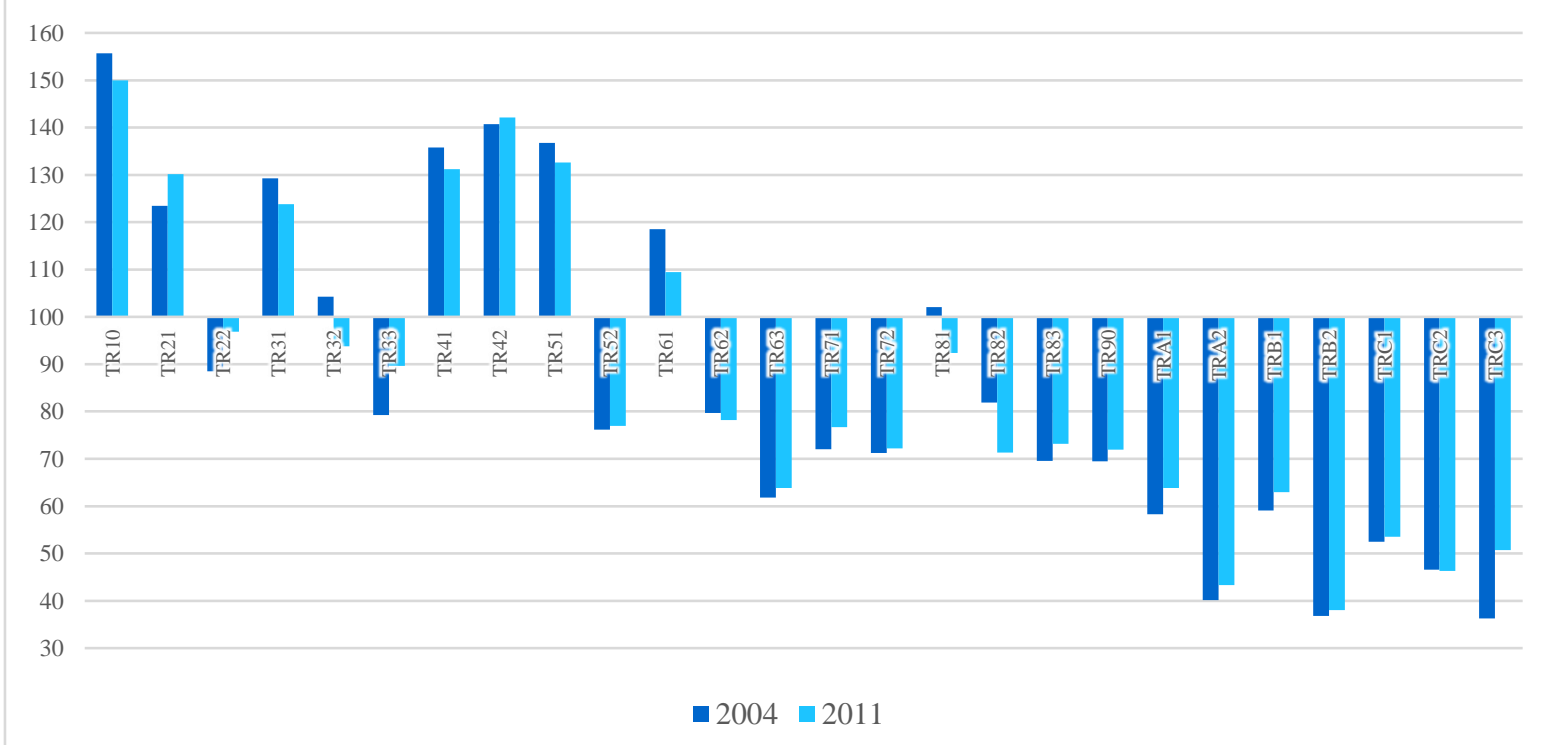

Source: TURKSTAT (2014)

\section{CONVERGENCE IN THEORY}

Neoclassical growth models developed by Solow (1956) and Swan (1956) have heavily influenced the convergence literature. In the Solow-Swan growth model, all economies are assumed to have the same production function and converge to a steady-state equilibrium. At the equilibrium, level of income per capita grows at an exogenous rate of technological change, while capital and output per unit of effective labor are constant. In this model, as there are diminishing returns to capital, economies with lower capital per unit of effective labor have higher rates of return and thus higher output growth rates. Therefore, for any given economy, it is expected that the lower the initial level of GDP per capita, the higher the growth rate. Thus, neoclassical growth model asserts that relatively poor economies converge to the rich ones over time.

On the other hand, endogenous growth theory pioneered by Romer (1986) and Lucas (1988) questioned the assumptions of diminishing returns to capital and decreasing returns to factors of production. This new theory made technological change and innovation endogenous to the growth models and regarded human capital accumulation, knowledge externalities and knowledge spillovers as the main drivers of economic growth. These endogenous drivers prevent the marginal product of physical capital from diminishing and asserts increasing returns to scale. This approach to economic growth argues that economies would not converge to the same steady state but rather to their own steady states conditioning on their basic initial conditions (conditional convergence). Thus, as opposed to absolute convergence prediction of neoclassical growth theory, endogenous growth theory implies divergence, and predicts the agglomeration of factors of production in certain places due to positive returns to scale. 
New economic geography (NEG) introduced by Krugman (1991) provided a new perspective into convergence debate by supporting neither convergence nor divergence assumptions. In the NEG, increasing return to scale, monopolistic competition, transport costs and externalities associated with agglomeration are fundamental to a proper understanding of spatial disparities. According to Krugman's core-periphery model, regional clusters and inequalities emerge due to a combination of "centrifugal forces" pulling economic activities together and "centripetal forces" pushing it apart. Depending on which force is stronger, models of new economic geography could generate regional divergence or convergence (Dawkins, 2003).

\section{EMPIRICAL STUDIES ON CONVERGENCE}

The growing interest on convergence in economic growth theory led to numerous empirical studies. First, the idea of beta $(\beta)$ convergence was introduced by Barro and Sala-i-Martin (1990) based on the theoretical framework developed by neoclassical growth theory. Beta convergence refers to the question of whether economies with low per capita income grow faster than the economies with relatively higher income per capita. This is to say that if convergence occurs, ceteris paribus, poor economies tend to catch up with wealthy ones. Even though the concept was developed by Barro and Sala-i-Martin (1990), Baumol (1986) and Abramovitz (1986) pioneered the application before its conceptualization. In his seminal work, Baumol (1986) found that the higher a country's initial productivity level in 1870, the slower that level grew in the 1870-1979 period. Similarly, Abramovitz (1986) proposed the catch-up hypothesis claiming that being backward in productivity level generates a potential for rapid advancement and implies a long-run tendency towards the equalization of income or productivity levels.

Beta convergence concept is further enhanced by Barro (1991) and Barro and Sala-i-Martin (1992) by bringing the idea that the poor and wealthy economies may not converge to the same steady-state. They categorize the convergence towards the same steady-state as absolute (or unconditional) and convergence towards the different steady-states as conditional convergence. In conditional convergence, they argue, the expected negative relationship between initial per capita income (or product per worker) level and growth rate holds only when the structural differences between poor and wealthy economies are held constant.

Some other researchers also suggested to test whether convergence occurs within the groups of similar economies, a phenomenon widely referred to as the club convergence hypothesis proposed firstly by Chatterji (1992) and further developed by Galor (1996). Like conditional convergence, club convergence analyses have almost always find convergence.

Another convergence concept, developed by Baumol (1986) and later named as sigma $(\sigma)$ convergence by Barro and Sala-i-Martin (1990) is related to the cross-sectional distribution of per capita income across economies. Within this concept if convergence occurs, ceteris paribus, the dispersion of per capita income across economies tends to decline and economies would be expected to converge to a common rate or level.

Following these influential papers, cross-country income convergence studies have proliferated. Similar discussions have taken place for state, regional, and provincial levels. Studies on income convergence across subnational units are pioneered by Barro and Sala-iMartin (1992) which found empirical evidence for convergence within the US states and European regions. Subsequently, Coulombe and Lee (1995) found absolute beta convergence 
for Canadian provinces; Cashin (1995) for Australian states; Sala-I-Martin (1996) for Japanese prefectures and regions of Germany, France, UK, Italy and Spain; Hofer and Wörgötter (1997) for Austrian regions; Persson (1997) for Swedish counties; Kangasharju (1998) for Finnish subregions; De La Fuente (2002) for Spanish regions; Michelis et al. (2004) for Greek regions; Serra et al. (2006) for Argentina, Brazil, Chile, Colombia, Mexico and Peru; and Eckey et al. (2007) for German regions. Conversely, other studies such as Mauro and Podrecca (1994) for Italian regions; Siriopoulos and Asteriou (1998) for Greek regions; Gripaios et al. (2000) for UK counties; Habibullah et al. (2008) for Malaysian regions; and Vidyattama (2013) for Indonesian regions did not find absolute beta convergence.

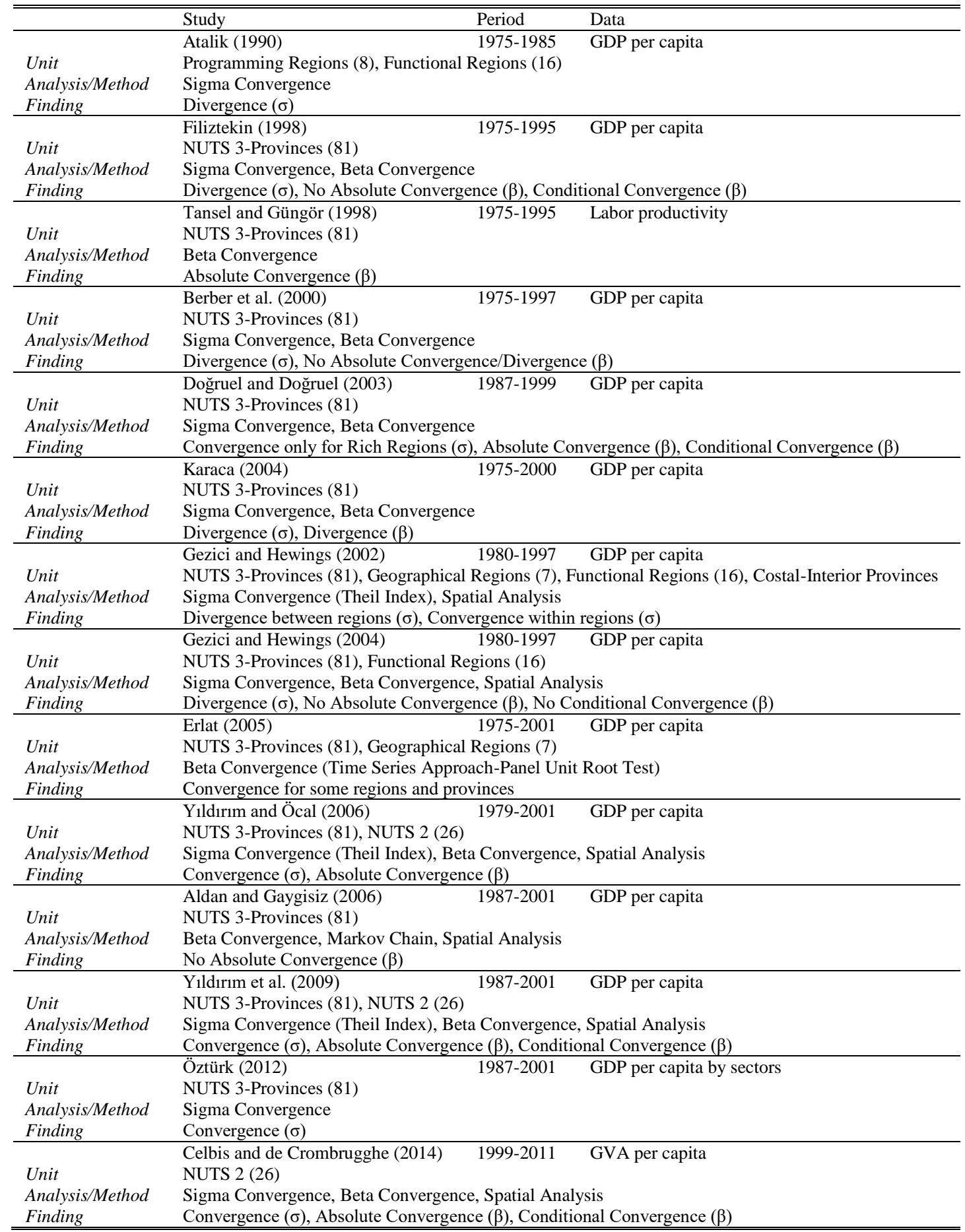

Table 3.1 Empirical Studies of Regional Convergence in Turkey. 
As the Treaty establishing the European Community defines economic and social cohesion as one of the main priorities of the European Union, the reduction of disparities between development levels of EU regions and Member States is seen as a key target of the European Cohesion Policy. Multiple studies have pointed out evidence of decreasing income disparities over time in Europe, especially across regions (Borsi and Metiu, 2015; Maza et al., 2012; Monfort, 2008).

As a reflection of this groundbreaking development in literature, empirical studies on regional disparities and convergence has also gained momentum in Turkey. Starting from the 1990s, researchers began to apply contemporary methods of sigma and beta convergence approaches into Turkey. As summarized in Table 3.1, findings of the literature on absolute convergence is inconclusive while conditional convergence hypothesis holds in almost all studies. We see that the presence of high level of spatial autocorrelation between regions/provinces in Turkey made spatial analysis and spatial econometrics methods an inevitable part of convergence analysis. On the other hand, we also see that most of these studies cover the period before 2001 in which traditional regional development policies were implemented. Empirical studies analyzing the trends of economic convergence after the implementation of the new regional development policies are very limited. Thus, this study will provide a valuable contribution to our understanding of regional convergence with current developments.

\section{METHOD}

There are several competing methods of testing convergence but none of them is capable of capturing all aspects of the process. This study focuses on sigma and beta convergence methods, as they are the two most common measures.

Existence of sigma convergence refers to the decline in the cross sectional dispersion of per capita income across economies. Beta convergence, however, tests whether the economies with low-income level grow faster than rich economies and implies the existence of a longer-term catch-up mechanism.

\subsection{Sigma Convergence and Static Measures of Regional Disparities}

There are several measures that can be used for measuring the sigma-convergence and changes in regional disparities. We use the following measures and methods: (i) Maximum to Minimum Ratio, (ii) Gini Index, (iii) Coefficient of Variation, (iv) Relative Mean Deviation, (v) Atkinson Index, (vi) Theil Index. A summary of these methods are presented in Table 4.2.

We calculated both unweighted and weighted versions of each indexes. The unweighted version assigns equal weight to each region regardless of its size, whereas the weighted version weights them by population proportions of the regions.

\subsection{Beta Convergence}

Sigma convergence present a snapshot view of regional disparities and dispersion of regional income. This is very helpful but not sufficient for understanding the convergence phenomenon. Beta convergence analysis, however, captures the growth dynamics between poor and rich regions by creating coefficients that directly measure the existence and magnitude of convergence. 


\begin{tabular}{|c|c|c|c|c|}
\hline & Indexes & \multicolumn{3}{|l|}{ Formula } \\
\hline & $\begin{array}{l}\text { Maximum to Minimum Ratio } \\
\text { (MMR) }\end{array}$ & & \multicolumn{2}{|c|}{$M M R=\frac{\text { GVA Per Capita }}{\text { max }}$} \\
\hline \multirow[t]{3}{*}{ Explanations } & \multicolumn{4}{|c|}{$\begin{array}{l}\text { If this ratio is small (close to 1), then it is easy to interpret that the regions have a relatively equal level of income but if it is large, then the } \\
\text { interpretation becomes more problematic. The presence of high ratio can be attributable to substantial variation in the distribution of GDP pe } \\
\text { capita (high regional disparities) or existence of outliers in the distribution. }\end{array}$} \\
\hline & \multirow[t]{2}{*}{40} & \multirow[b]{2}{*}{ Unweighted } & \multicolumn{2}{|c|}{$G_{u}=\left(\frac{1}{2 \bar{y}_{u}}\right) \frac{1}{N(N-1)} \sum_{i}^{n} \sum_{j}^{n}\left|y_{i}-y_{j}\right|$} \\
\hline & & & \multicolumn{2}{|l|}{$G_{u}=\frac{2}{N-1} \sum_{i=1}^{N-1}\left|F_{i}-Q_{i}\right|$} \\
\hline \multirow[t]{2}{*}{ Explanations } & \multicolumn{4}{|c|}{$\begin{array}{l}\text { It varies between } 0 \text { and } 1 . \text { The value of } 0 \text { represents "perfect equality" where each region has an equal share. On the other hand, the value of } \\
1 \text { represents "complete inequality" where income is concentrated in one region. }\end{array}$} \\
\hline & Gini & Weighted & \multicolumn{2}{|c|}{$\mathrm{G}_{\mathrm{w}}=\left(\frac{1}{2 \overline{\mathrm{y}}}\right) \sum_{1}^{\mathrm{n}} \sum_{j}^{\mathrm{n}}\left|\mathrm{y}_{\mathrm{i}}-\mathrm{y}_{\mathrm{j}}\right| \frac{\mathrm{p}_{\mathrm{i}} \mathrm{p}_{\mathrm{j}}}{\mathrm{p}^{2}}$} \\
\hline \multirow[t]{2}{*}{ Explanations } & \multicolumn{4}{|c|}{$\begin{array}{l}\text { It varies between } 0 \text { for perfect equality and } 1-(\mathrm{p} / \mathrm{p}) \text { for perfect inequality. If } \mathrm{p}_{\mathrm{i}} \text { is small compared to } \mathrm{p} \text {, i.e., if the region with a small } \\
\text { proportion of the population produced all the GDP then the value for perfect inequality would approach } 1 .\end{array}$} \\
\hline & Coefficient of Variation (CV) & Unweighted & \multicolumn{2}{|c|}{$C V_{u}=\frac{\sqrt{\sum_{i=1}^{N} \frac{\left[y_{i}-\bar{y}_{u}\right]^{2}}{N}}}{\bar{y}_{u}}$} \\
\hline Explanations & \multicolumn{4}{|c|}{ It varies from 0 for perfect equality to $\sqrt{N-1}$ for perfect inequality. } \\
\hline & & Weighted & \multicolumn{2}{|l|}{$C V_{w}=\frac{\sqrt{\sum_{i=1}^{N}\left[y_{i}-\bar{y}\right]^{2} \frac{p_{i}}{p}}}{\bar{y}}$} \\
\hline \multirow[t]{2}{*}{ Explanations } & \multicolumn{4}{|c|}{ It varies from 0 for perfect equality to $\sqrt{\left(p-p_{i}\right) p_{i}}$ for perfect inequality where a single region generates the entire national GDP. } \\
\hline & Relative Mean Deviation (RMD) & Unweighted & \multicolumn{2}{|c|}{$R M D_{u}=\frac{1}{2 \bar{y}_{u}}\left[\frac{1}{N} \sum_{i=1}^{N}\left|y_{i}-\bar{y}_{u}\right|\right]$} \\
\hline Explanations & \multicolumn{4}{|c|}{ It varies from 0 for perfect equality to $(\mathrm{N}-1) / \mathrm{N}$ for perfect inequality. } \\
\hline & Relative Mean Deviation (RMD) & Weighted & \multicolumn{2}{|l|}{$R M D_{w}=\frac{\sum_{i=1}^{N}\left|y_{i}-\bar{y}\right| \frac{p_{i}}{p}}{\bar{y}}$} \\
\hline \multirow[t]{5}{*}{ Explanations } & \multicolumn{4}{|c|}{ It varies from 0 for perfect equality to 2 for perfect inequality. } \\
\hline & \multirow{4}{*}{ Atkinson } & \multirow{2}{*}{ Unweighted } & $A_{u}=1-\left[\frac{1}{N} \sum_{i=1}^{N}\left[\frac{y_{i}}{\bar{y}_{u}}\right]^{1-\varepsilon}\right]^{\frac{1}{1-\varepsilon}}$ & $\varepsilon \neq 1$ \\
\hline & & & $A_{u}=1-\frac{\prod_{i=1}^{N}\left[\left[y_{i}\right]^{\frac{1}{N}}\right]}{\bar{y}_{u}}$ & $\varepsilon=1$ \\
\hline & & \multirow{2}{*}{ Weighted } & $A_{w}=1-\left[\sum_{i=1}^{N}\left[\frac{y_{i}}{\bar{y}}\right]^{1-\varepsilon}\left[\frac{p_{i}}{p}\right]\right]^{\frac{1}{1-\varepsilon}}$ & $\varepsilon \neq 1$ \\
\hline & & & $A_{w}=1-\left[\sum_{i=1}^{N}\left[\frac{y_{i}}{\bar{y}}\right]^{1-\varepsilon}\left[\frac{p_{i}}{p}\right]\right]^{\frac{1}{1-\varepsilon}}$ & $\varepsilon=1$ \\
\hline \multirow[t]{5}{*}{ Explanations } & \multicolumn{4}{|c|}{ 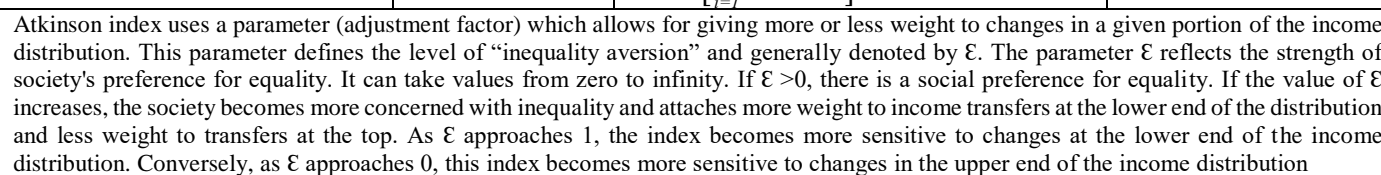 } \\
\hline & \multirow{2}{*}{$\begin{array}{l}\text { Theil Index - Theil's L/ } \\
\text { Mean Log Deviation (MLD) }\end{array}$} & Unweighted & $M L D_{(u)}(\alpha)=\frac{1}{N} \sum_{i=1}^{N} \log \left[\frac{\bar{y}_{u}}{y_{i}}\right]$ & \multirow{2}{*}{$\alpha=0$} \\
\hline & & Weighted & $M L D_{(w)}(\alpha)=\sum_{i=1}^{N}\left[\frac{p_{i}}{p}\right] \log \left[\frac{\bar{y}}{y_{i}}\right]$ & \\
\hline & \multirow{2}{*}{ Theil Index -Theil's T } & Unweighted & $\operatorname{Theil}_{(u)}(\alpha)=\frac{I}{N} \sum_{i=l}^{N} \frac{y_{i}}{\bar{y}_{u}} \log \left[\begin{array}{l}y_{i} \\
\bar{y}_{u}\end{array}\right]$ & \multirow{2}{*}{$\alpha=1$} \\
\hline & & Weighted & $\operatorname{Theil}_{(w)}(\alpha)=\sum_{i=1}^{N}\left[\frac{p_{i}}{p}\right]\left[\frac{y_{i}}{\bar{y}}\right] \log \left[\frac{y_{i}}{\bar{y}}\right]$ & \\
\hline Explanations & $\begin{array}{l}\text { Theil Index is a member of the fa } \\
\text { with zero representing an equal } \\
\text { indicates the weight given to diste } \\
\text { values of } \alpha, \mathrm{GE} \text { is more sensitive } \\
\text { affect the upper tail. The common }\end{array}$ & $\begin{array}{l}\text { of the Generali } \\
\text { ution and high } \\
\text { between incom } \\
\text { anges in the lov } \\
d \text { values of } \alpha \text { a }\end{array}$ & $\begin{array}{l}\text { ropy (GE) inequality measures. Th } \\
\text { es representing higher levels of in } \\
\text { ferent parts of the income distribu } \\
\text { of the distribution, and for higher } \\
\text { nd } 2 \text {. }\end{array}$ & $\begin{array}{l}\text { ranges from zero to infinity, } \\
\text { arameter } \alpha \text { in the GE class } \\
\text { ke any real value. For lower } \\
\text { ore sensitive to changes that }\end{array}$ \\
\hline
\end{tabular}

Table 4.2 Sigma Convergence and Static Measures of Regional Disparities.

Source: Shankar and Shah, 2003; Haughton and Khandker, 2009; Monfort, 2008; Kakwani, 1980, 1988, 1990; OECD, 2013; Williamson, 1965; Wahiba, 2014; Atkinson, 1970, 1975, 1983; Shahateet, 2006; Litchfield, 1999; Theil, 1967; Banerjee and Kuri, 2015.

Notes: $y_{i}$ and $y_{j}$ are the GVA per capita of region $i$ and $j$ respectively; $N$ is the number of regions; $\bar{y}_{u}$ is the unweighted (arithmetic) mean of the per capita GVA of regions $\bar{y}_{u}=\sum_{i=1}^{N} y_{i} / N ; \mathrm{F}_{\mathrm{i}}$ is $F_{i}=i / N ; Q_{i}$ is $Q_{i}=\sum_{j=1}^{i} y_{j} / \sum_{i=1}^{N} y_{i}$ (where $y_{i}$ is the value of variable y (e.g. GVA per capita) in region $\mathrm{j}$ when ranked from low $\left(y_{i}\right)$ to high $\left(y_{N}\right)$ among all regions within a country); $p_{i}$ and $p_{j}$ are the populations of region $i$ and $j$ respectively; $p$ is the national population; $\bar{y}$ is the national GVA per capita. 
There are two specifications of beta convergence: (i) absolute (unconditional) convergence and (ii) conditional convergence. This paper studies absolute regional convergence for two reasons. Firstly, even though conditional convergence has also been widely studied in the literature, absolute convergence is far more relevant in policy discussions. This is due to the fact that the question of whether Turkish regions are converging has many more practical implications than the question of where (i.e a common or a specific steady-state) Turkish regions are converging. Therefore, reducing the regional development disparities in "absolute terms" has been a major policy issue in Turkey since 1960s, not the structure of this convergence. Secondly, structural differences across regions are expected to be much smaller than they are across countries given the fact that regions are under the same macroeconomic policy environment. This makes conditional convergence studies relatively less important for sub-national units than they are across countries.

The first comprehensive method for measuring beta convergence across economies is introduced by Barro and Sala-i-Martin $(1990,1991,1992)$ using the following equation:

$$
\frac{1}{T} \log \left[\frac{y_{i, t+T}}{y_{i t}}\right]=\alpha-\left[\frac{1-e^{-\beta T}}{T}\right] \log \left[y_{i t}\right]+u_{i t}
$$

where $i$ denotes the economy, $t$ indexes time, $y$ is per capita income, $T$ is the length of the observation interval, the coefficient $\beta$ is the rate of convergence, and $u$ is an error term. For our purposes, the equation (4.1) can be rearranged and simply estimated by the following equation:

$$
\log \left[\frac{y_{i, t+T}}{y_{i t}}\right]=\alpha+\gamma \log \left[y_{i t}\right]+u_{i t}
$$

where $\gamma$ is the coefficient to be estimated for detecting the convergence. A negative value of $\gamma$ indicates convergence. The convergence rate/speed can be calculated by using the following equality:

$$
\begin{gathered}
\gamma=-\left[1-e^{-T \beta}\right] \\
\text { Convergence Speed }-\beta=-\frac{\ln [1+\gamma]}{T}
\end{gathered}
$$

In addition, another common indicator to characterize the speed of convergence is half-life $(\tau)$, defined as the necessary period for half of the initial income inequalities to disappear. It is calculated as follows:

$$
\tau=\frac{\ln [2]}{\beta}
$$

\subsection{Spatial Autocorrelation}

In the literature, beta convergence analyses have only recently been performed by taking spatial effects into account. Moreover, empirical studies measuring regional convergence from a spatial econometric perspective have showed that spatial externalities and spillovers are highly important in the analysis of growth patterns and provided richer insights to regional economic growth and convergence process (Rey and Montouri, 1999). Thus spatial autocorrelation should be considered in regional analyses. Spatial autocorrelation is defined as the correlation among values of a single variable strictly attributable to the proximity of those values in geographic space, introducing a deviation from the independent observations assumption of classical statistics (Griffith, 2003). The most common measure of spatial dependence is Moran's I, due to the fact that it gives a powerful measurement and it is sensitive to extreme values (Cliff and Ord, 1975).

Moran's I statistics provide tests and visualization of both global spatial autocorrelation (test for spatial pattern and clustering) and local spatial autocorrelation (test for spatial clusters) (Celebioğlu and Dall'erba, 2010). Global spatial autocorrelation is measured by using Moran's I, defined as (Anselin, 1988, 1995): 


$$
I=\frac{N}{\sum_{i=1}^{N} \sum_{j=1}^{N} w_{i j}} \frac{\sum_{i=1}^{N} \sum_{j=1}^{N} w_{i j}\left[y_{i}-\bar{y}\right]\left[y_{j}-\bar{y}\right]}{\sum_{i=1}^{N}\left[y_{i}-\bar{y}\right]^{2}}
$$

where $N$ is the number of regions, $y_{i}$ is the GDP per capita of region $i, y_{j}$ is the GDP per capita of region $j, \bar{y}$ is the average GDP per capita for all regions, and $w_{i j}$ is an element of standardized binary spatial weights matrix $(W)$ using queen contiguity neighborhood structure.

Global spatial autocorrelation as a measure of overall clustering is used to test the null hypothesis of "no spatial association" or "spatial randomness" which assumes the absence of any spatial pattern, while local spatial autocorrelation is a local spatial statistic assessing the significance for each location and allows for the decomposition of global indicators.

Local spatial autocorrelation indicates to what extent each location is surrounded by neighbors having similar or dissimilar values, so it is used to identify spatial clusters and spatial outliers: (i) Spatial Clusters: positive and significant local spatial autocorrelation: (High-High $(\mathrm{HH})$ : a high income region with high income neighbors) and (Low-Low (LL): a low income region with low income neighbors); (ii) Spatial Outliers: negative and significant local spatial autocorrelation: (High-Low (HL): a high income region with low income neighbors) and (LowHigh (LH): a low income region with high income neighbors. It is calculated by using local Moran's I statistic (Anselin, 1995):

$$
I_{i}=\frac{\left[y_{i}-\bar{y}\right]}{\frac{1}{N} \sum_{i=1}^{N}\left[y_{i}-\bar{y}\right]^{2}} \sum_{j=1}^{N} w_{i j}\left[y_{j}-\bar{y}\right]
$$

Moran's I statistics as a measure of spatial autocorrelation basically provides descriptive statistics to determine the existence of spatial dependence. In the existence of significant spatial autocorrelation, it is needed to include spatial parameters and interaction into econometric analysis designed for testing beta convergence hypothesis.

\subsection{Spatial Econometric Models}

Spatial autocorrelation can be handled through three different types of interaction effects explaining why an observation associated with a specific location may be dependent on observations at other locations (Elhorst, 2014): (i) endogenous interaction effects among the dependent variable $(Y)$; (ii) exogenous interaction effects among the independent variables $(X)$; (iii) interaction effects among the error terms $(e)$.

Elhorst (2014) develops a general nesting spatial model containing all types of interaction effects as follows:

$$
\begin{gathered}
Y=\alpha+\delta W Y+X \beta+W X \theta+\mu \\
\mu=\lambda W \mu+\varepsilon
\end{gathered}
$$

where $W$ is the spatial weights matrix, $W Y$ denotes the endogenous interaction effects among the dependent variable, $W X$ denotes the exogenous interaction effects among the independent variables, $\mathrm{Wu}$ denotes the interaction effects among the disturbance term of the different units, $\varepsilon$ is the independent and identically distributed error term.

We can customize the above general model for our analysis on beta convergence as follows:

$$
\begin{gathered}
\log \left[\frac{y_{i, t+T}}{y_{i t}}\right]=\alpha+\delta W \log \left[\frac{y_{i, t+T}}{y_{i t}}\right]+\gamma \log \left[y_{i t}\right]+\theta W \log \left[y_{i t}\right]+u_{i t} \\
u_{i t}=\lambda W u_{i t}+\varepsilon_{i t}
\end{gathered}
$$

Then, three most common linear spatial econometric models can be derived by imposing restrictions on one or more of parameters $(\delta, \theta, \lambda)$ of the general nesting spatial model. 
First, Spatial Error Model (SEM) assumes that the spatial dependence works through the error process due to the omitted random factors such that the errors from different regions may have spatial covariance (Rey and Montouri, 1999). It can be expressed as:

$$
\begin{gathered}
\log \left[\frac{y_{i, t+T}}{y_{i t}}\right]=\alpha+\gamma \log \left[y_{i t}\right]+u_{i t} \\
u_{i t}=\lambda W u_{i t}+\varepsilon_{i t}
\end{gathered}
$$

Secondly, Spatial Lag Model (SLM) examines how GDP per capita growth rates of regions are related not only to their own initial level of income but also to the growth rates of neighboring regions which can be expressed as:

$$
\log \left[\frac{y_{i, t+T}}{y_{i t}}\right]=\alpha+\gamma \log \left[y_{i t}\right]+\delta W \log \left[\frac{y_{i, t+T}}{y_{i t}}\right]+u_{i t}
$$

Thirdly, The SAC Model ${ }^{1}$ includes both a spatially lagged dependent variable and a spatially auto-correlated error term.

$$
\begin{gathered}
\log \left[\frac{y_{i, t+T}}{y_{i t}}\right]=\alpha+\delta W \log \left[\frac{y_{i, t+T}}{y_{i t}}\right]+\gamma \log \left[y_{i t}\right]+u_{i t} \\
u_{i t}=\lambda W u_{i t}+\varepsilon_{i t}
\end{gathered}
$$

\section{DATA}

The analyses concentrate on the 2004-2011 period and use real GVA per capita values for Turkish NUTS II regions at 1998 prices. The spatial level (i.e NUTS II instead of NUTS III) and the unit of analysis (i.e GVA instead of GDP) are not preferences but obligations due to lack of data.

\section{FINDINGS}

\subsection{Sigma Convergence and Static Measures of Regional Disparities}

The box plot presented in Figure 6.4 shows that all the regions increased their income per capita and also variation in regional income per capita decreased in 2004-2011 period. When the variation is decomposed for shorter time frames, we see that it increased between 2004 and 2007. This is the period when Turkey experienced real economic expansion. Then, we see a reduction in the dispersion of regional income per capita in 2008 and 2009. These are the years when Turkey felt the impact of the 2008 financial crisis, and also experienced sigma convergence. When we check the income per capita growth rates of regions in these crisis years, we notice that while developed regions located in the western part of the country were experiencing a negative income per capita growth, relatively poorer regions located in the eastern part were either only slightly affected by the crisis or achieved growth. This is the main reason behind the sigma converge achieved in 2008 and 2009. Moreover, we see that dispersion began to rise again after 2010 in parallel to the increasing growth performance of the country. Thus, our findings on sigma convergence are in line with the literature which reports that interregional inequality decreases in the recession periods and increases in the economic expansion periods.

Figure 6.5 shows that all inequity measures of sigma convergence follow more or less the same trend in the box plot and support our findings of sigma convergence. Inequality decreased in

\footnotetext{
${ }^{1}$ This model is denoted by the term SAC in LeSage and Pace (2009), though without pointing out what this acronym is standing for (Elhorst, 2014).
} 
2005 and increased in 2006 for all indexes. We start to see a reduction in equality again between 2006 and 2010 for the MMR, Gini Index, CV and RMD and between 2008 and 2010 for the Atkinson Index and Theil Index. On the other hand, it should be noted that for most of the measures, the weighted values are larger than the unweighted values. This indicates that the regions with extreme/high per capita GVAs are generally those with larger populations. As a result, we can conclude that descriptive evidence based on static measures of regional inequalities support the hypothesis of sigma convergence between 2004-2011.

Figure 6.4 Dispersion of GVA per capita of NUTS II Regions

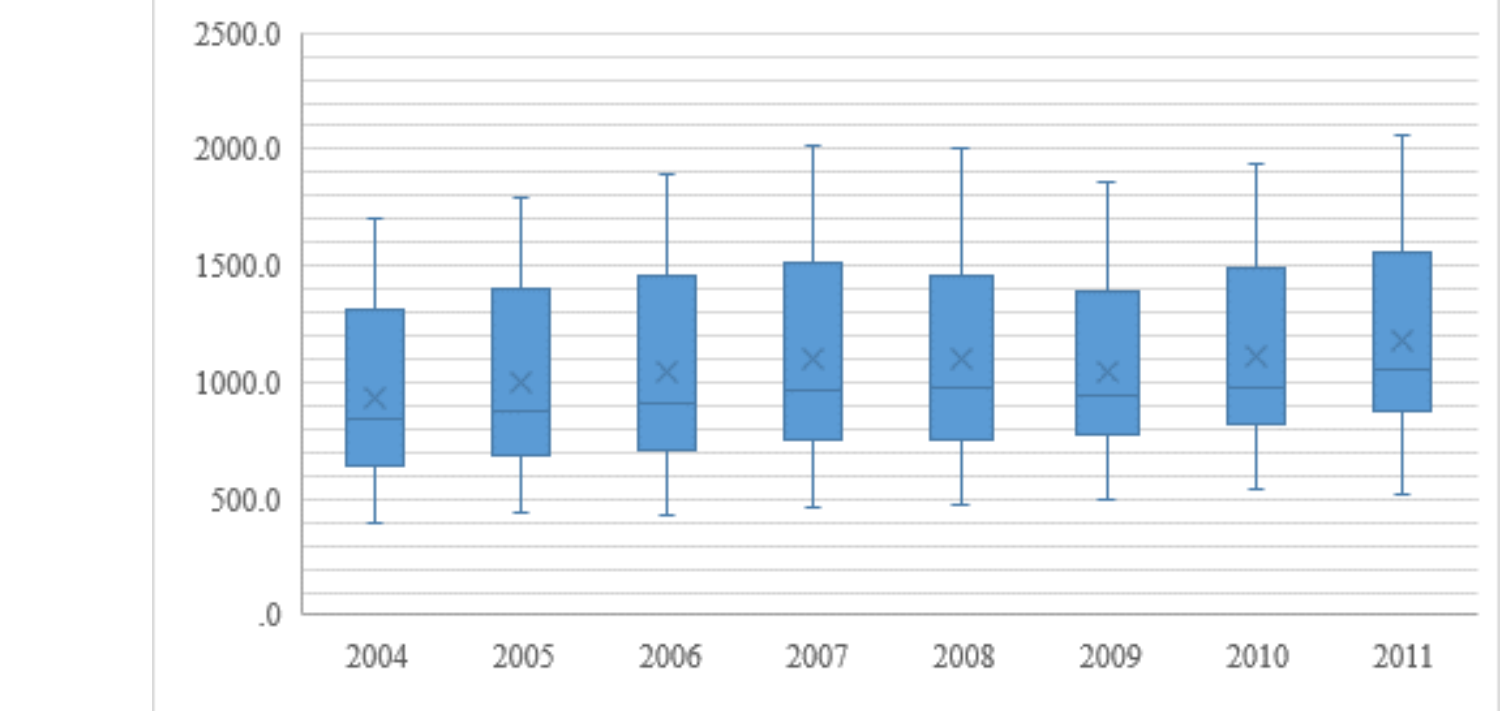

Source: TURKSTAT (2014)

\begin{tabular}{ccccccc}
\hline \hline GVA per capita/Years & Moran's $I$ & $\mathrm{E}(I)$ & $\mathrm{sd}(I)$ & $z$ & $p$-value & \# of obs. \\
\hline 2004 & 0.654 & -0.040 & 0.131 & 5.313 & 0.000 & 26 \\
2005 & 0.656 & -0.040 & 0.131 & 5.315 & 0.000 & 26 \\
2006 & 0.651 & -0.040 & 0.131 & 5.282 & 0.000 & 26 \\
2007 & 0.656 & -0.040 & 0.130 & 5.331 & 0.000 & 26 \\
2008 & 0.684 & -0.040 & 0.130 & 5.549 & 0.000 & 26 \\
2009 & 0.676 & -0.040 & 0.130 & 5.492 & 0.000 & 26 \\
2010 & 0.669 & -0.040 & 0.130 & 5.435 & 0.000 & 26 \\
2011 & 0.682 & -0.040 & 0.130 & 5.534 & 0.000 & 26 \\
\hline \hline
\end{tabular}

Table 6.3 Global Moran's I for GVA per capita

Notes: E[I]: expected value of Moran's $I$ statistic $=-1 /(n-1) . \mathrm{Sd}(I)$ : standard error of Moran's $I$ computed from its simulated distribution. $z$ : $z$ score calculated for the randomization null hypotheses test. $p$-value: pseudo $p$-value obtained from one-tailed test.

\subsection{Spatial Dependence in Turkish Regions}

Figure 6.6 provides a disaggregated view of the nature of the spatial autocorrelation diagnostics for GVA per capita for the years 2004 and 2011. It shows that there is a highly significant positive spatial autocorrelation i.e. the value of GVA per capita in a region depends positively on the values in the neighboring regions. The figure also reveals that most of the regions are located in the quadrants I (HH) and III (LL): western regions with high income values are mainly located in the quadrant $1(\mathrm{HH})$ while eastern region with low income values are mainly located in the quadrant 3 (LL). Table 6.3, which displays the Moran's I statistic calculated for each year, supports our finding of statistically significant positive spatial autocorrelation for GVA per capita across NUTS II regions because Moran's I values are very different from the expect values and p-values are less than 0.05 . 
Figure 6.5 Static Measures of Regional Disparities

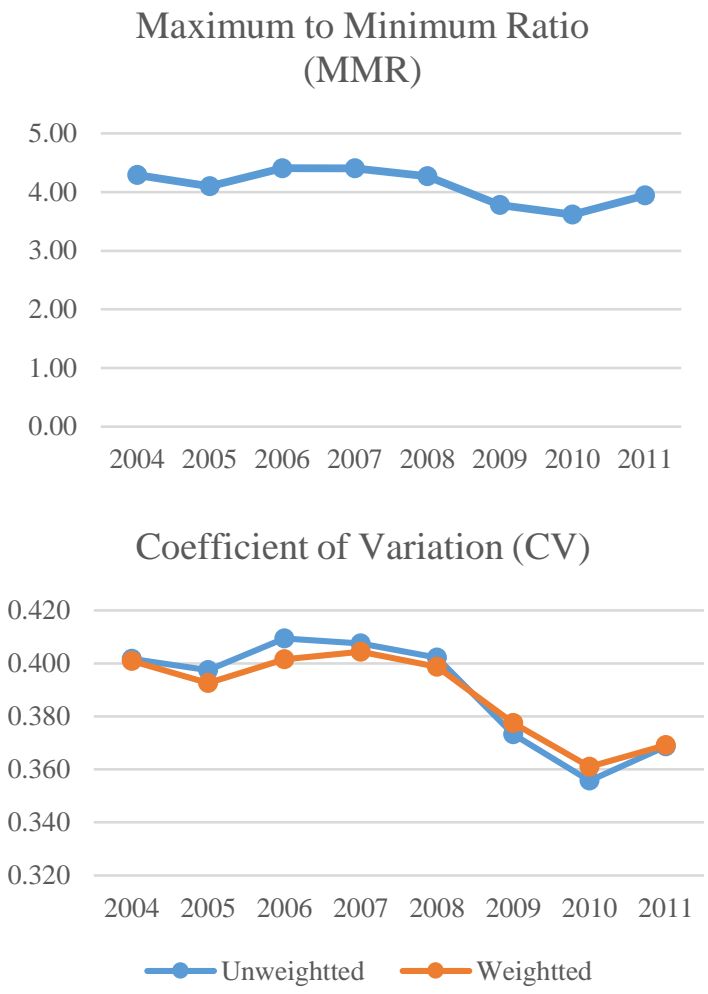

Atkinson Index

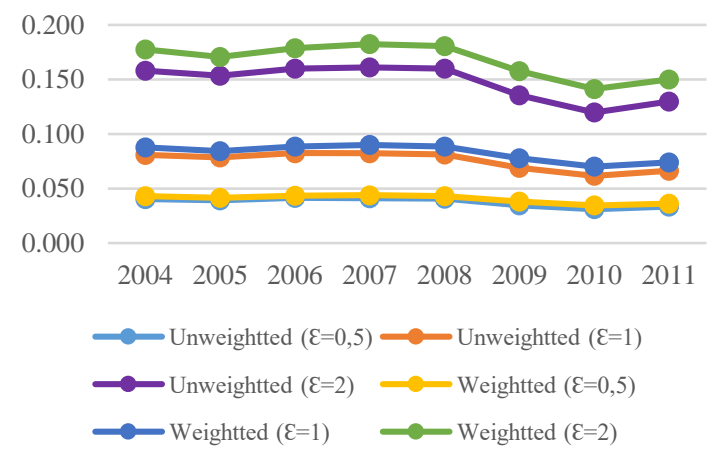

Gini Index

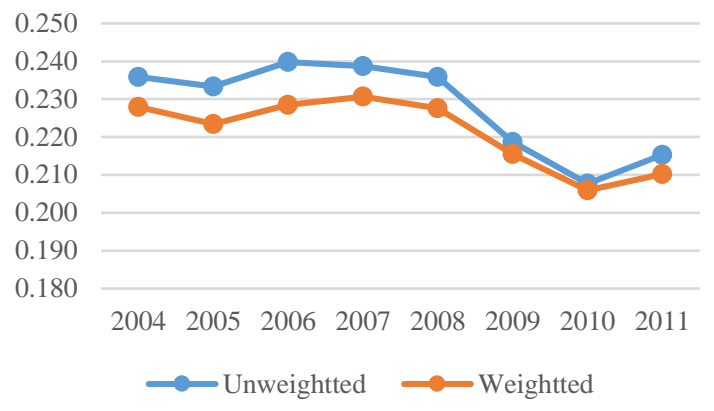

Relative Mean Deviation (RMD)

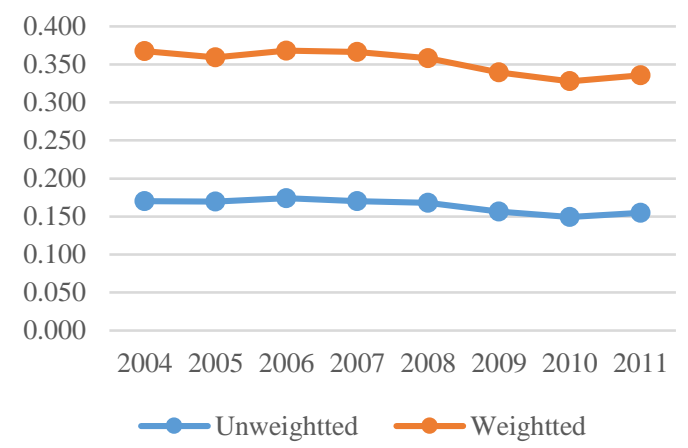

Theil Index

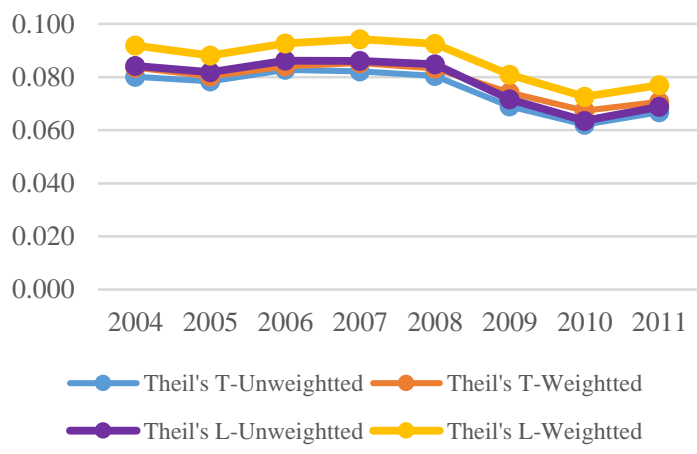

In Figure 6.6, the Moran scatter plots on the left visualize the relationship between the standardized GVA per capita of a region and its spatial lag (GVA per capita of the neighboring regions). The slope of the regression line corresponds to the Moran's I statistic. Moran's I statistics are obtained through permutation approach (999 permutations). LISA maps display spatial clusters and outliers obtained after the pseudo significance test generated under permutation approach.

When we analyze the Moran's I statistics for the growth rate of GVA per capita presented in Table 6.4 and Figure 6.7 the value of growth rate for 2004-2011 period is not significant but positive. LISA (Local Indicators of Spatial Association) map presented in Figure 6.7 shows that $\mathrm{HH}$ clusters are mainly located in eastern part of the country (lagging behind area) while LL clusters are mainly located in the western part (developed area). 
Figure 6.6 Moran's I Statistics for GVA per capita of NUTS II Regions GVA per capita, 2004
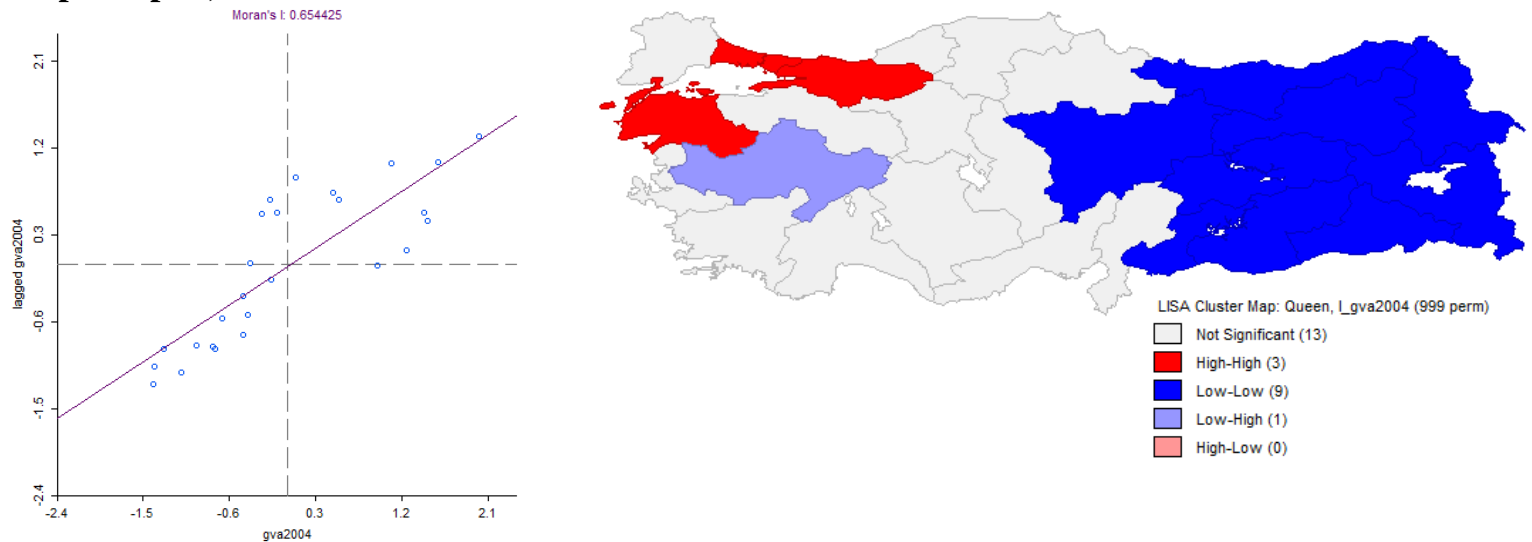

GVA per capita, 2011
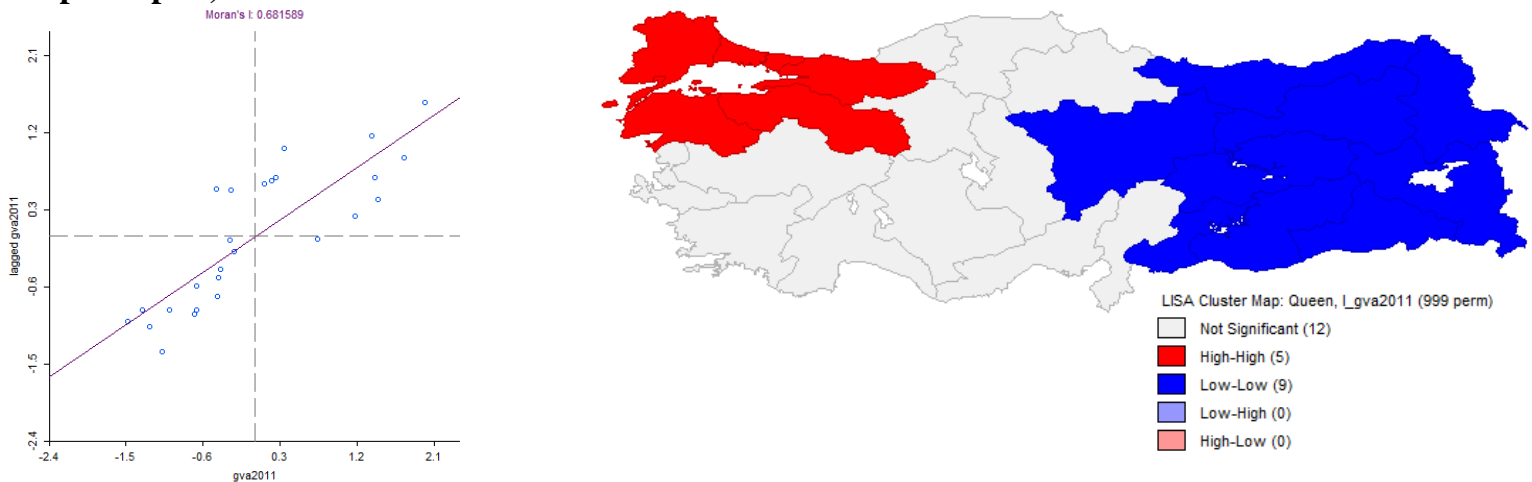

\begin{tabular}{ccccccc}
\hline \hline Growth Rate/Periods & Moran's $I$ & $\mathrm{E}(I)$ & $\mathrm{sd}(I)$ & $z$ & $p$-value* & \# of obs. \\
\hline $2004-2011$ & 0.062 & -0.040 & 0.116 & 0.876 & 0.190 & 26 \\
$2004-2005$ & -0.227 & -0.040 & 0.124 & -1.506 & 0.066 & 26 \\
$2005-2006$ & -0.140 & -0.040 & 0.128 & -0.782 & 0.217 & 26 \\
$2006-2007$ & 0.109 & -0.040 & 0.128 & 1.157 & 0.124 & 26 \\
$2007-2008$ & -0.021 & -0.040 & 0.129 & 0.145 & 0.442 & 26 \\
$2008-2009$ & 0.594 & -0.040 & 0.130 & 4.894 & 0.000 & 26 \\
$2009-2010$ & 0.370 & -0.040 & 0.126 & 3.245 & 0.001 & 26 \\
$2010-2011$ & 0.156 & -0.040 & 0.126 & 1.556 & 0.060 & 26 \\
\hline \hline
\end{tabular}

Table 6.4 Global Moran's I for Growth Rate of GVA per capita

Notes: Moran's I: Moran statistic for GVA per capita. E[I]: expected value of Moran's $I$ statistic $=-1 /(n-1)$. $\operatorname{sd}(\mathrm{I})$ : standard error of Moran's $I$ computed from its simulated distribution. $z$ : $z$-test statistic. $p$-value: pseudo $p$-value obtained from one-tailed test.

On the other hand, when we look at the yearly based Moran's $I$ statistic in Table 6.4, we see that 4 of 7 test statistics indicate positive spatial autocorrelation and 2 of them (2008-2009 and 2009-2010) are highly statistically significant. 4 of the 8 test statistics in the table produce statistically significant results at the $10 \%$ significance level. In addition, LISA maps for the 2008-2009 and 2009-2010 periods more clearly points out that HH clusters with high growth rate of GVA per capita are located in the eastern part of the country whereas LL clusters with low growth rate values are located in the Marmara and Western Black Sea regions. In addition, Figure $6.7 \mathrm{~b}$ shows the fact that developed regions were hit more by the crisis, while developing regions were more resilient to the external shock in 2008. Similarly, Figure 7c shows that growth rates picked up faster in developing regions right after the crisis compared to the developed ones. 
Figure 6.7 Moran's I Statistics for Growth Rate of GVA per capita a. Growth Rate of GVA per capita, 2004-2011
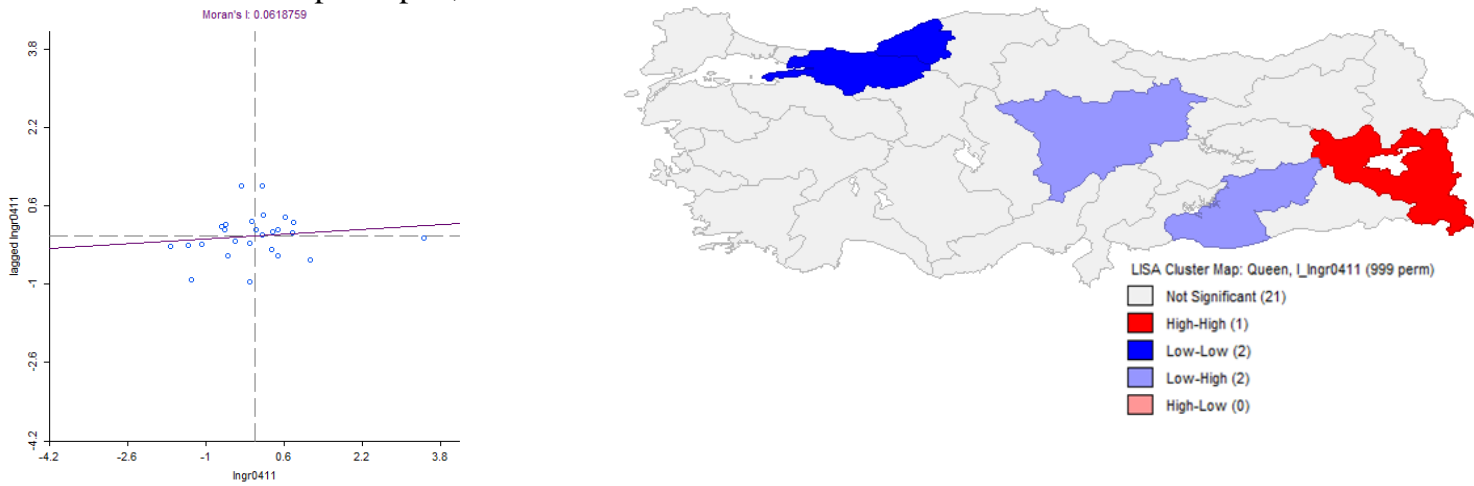

b. Growth Rate of GVA per capita, 2008-2009
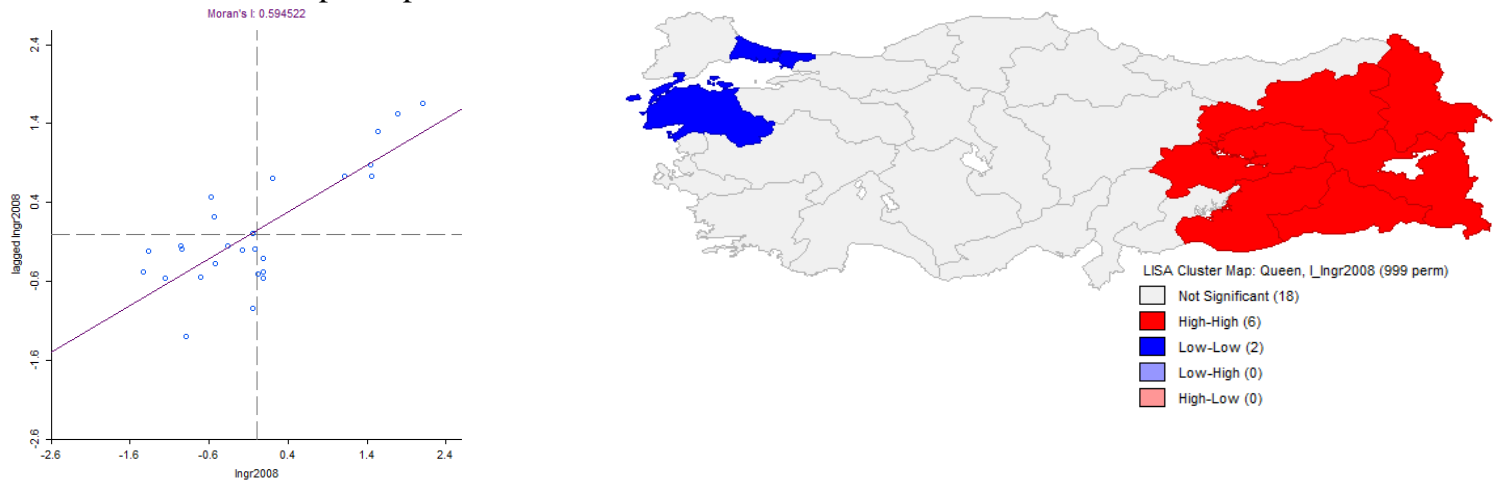

c. Growth Rate of GVA per capita, 2009-2010
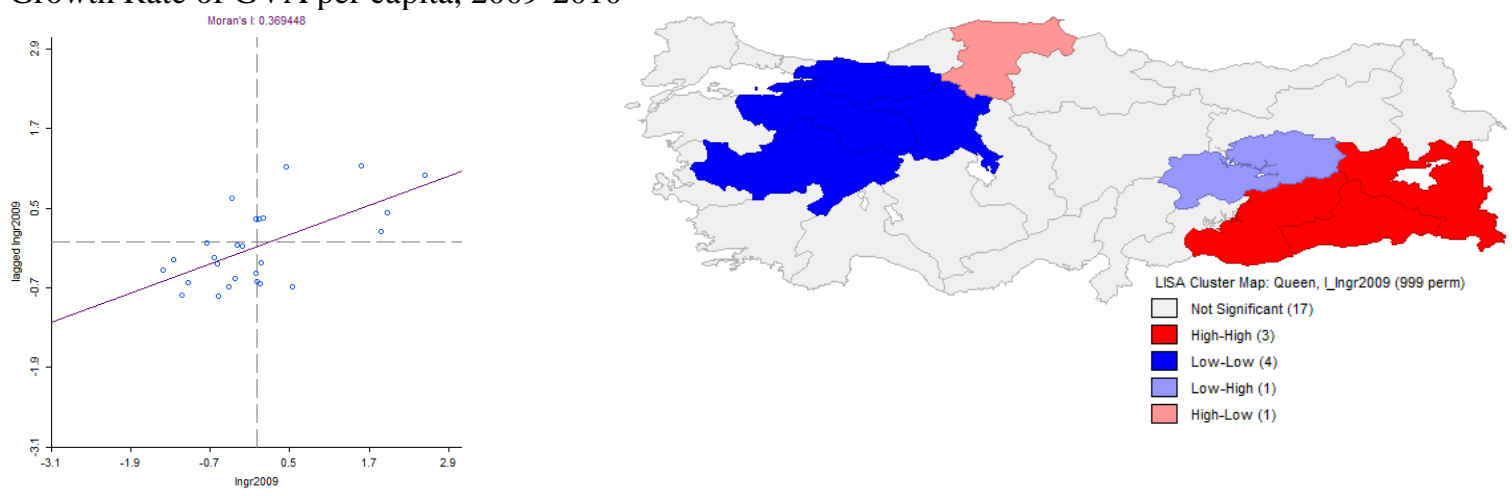

\subsection{Beta Convergence}

If the beta convergence hypothesis holds, we expect to see a negative correlation between per capita income growth rate and initial per capita income levels of regions. Figure 6.8 displays the negative slope of the fitted regression line.

In order to test the beta convergence hypothesis, we estimated regression models for equations (4.2), (4.9), (4.10) and (4.11) in both cross-sectional and panel data settings. Table 6.5 presents the estimation results for cross-sectional settings. The dependent variable for all models is the growth rate of GVA per capita of NUTS II regions for the period of 2004-2011. The main explanatory variable in all models is GVA per capita of NUTS II regions in 2004. We also included two other explanatory variables to control for spatial dependence. We first estimated the OLS model. Then, we extended the traditional OLS model by integrating spatial effects in three ways: first, by adding interaction effects among of the growth rates of GVA per capita of regions (SAR model) and later by adding interaction effects among the error terms (SEM 
model). Thirdly, we estimate the SAC model, which includes both of these two endogenous effects.

Figure 6.8 Scatterplot of Income Growth Rate by Initial Income

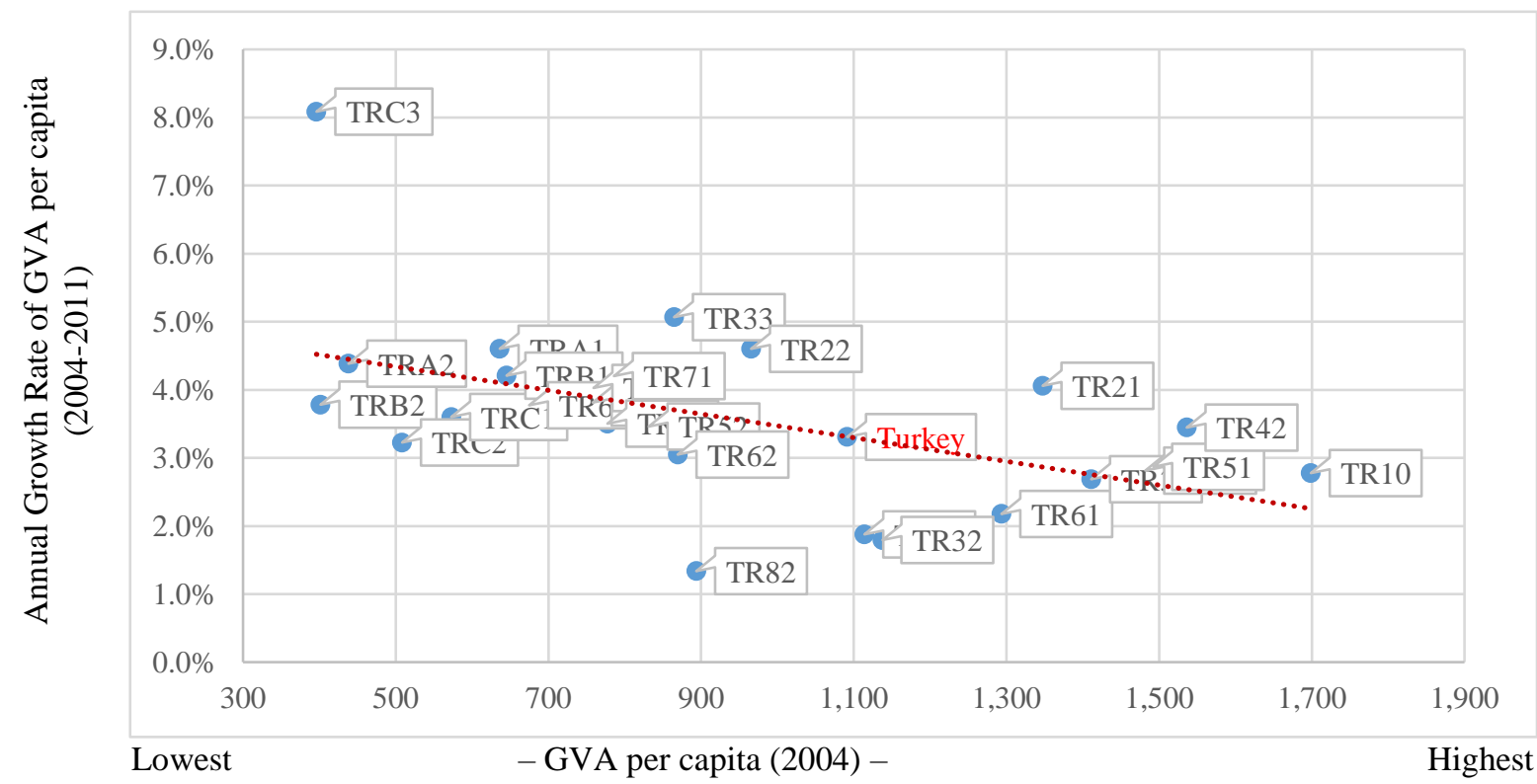

\begin{tabular}{lcccc}
\hline \hline & OLS & SAR & SEM & SAC \\
\hline Dependent Variable: & & GVA pc growth rate & $-0.125^{* *}$ \\
\hline In (initial GVA pc) & $-0.121^{* *}$ & $-0.132^{* * *}$ & $-0.113 * * *$ & $(0.0568)$ \\
$W^{*}$ GVA pc & $(0.0464)$ & $(0.0466)$ & $(0.0306)$ & -0.142 \\
growth rate & & -0.225 & $(0.578)$ \\
$W^{*}$ Error term & & $(0.306)$ & & -0.0994 \\
& & & -0.230 & $(0.601)$ \\
Constant & & & $(0.304)$ & $(0.891 * *$ \\
Convergence Speed & $1.899 * * *$ & $2.110 * * *$ & $1.795 * * *$ & 0.019 \\
Half-life Period & $(0.640)$ & $(0.678)$ & $(0.418)$ & 36 Years \\
Observations & 0.018 & 0.020 & 0.017 & 26 \\
$R$-sq & 38 Years & 34 Years & 40 Years & 0.3150 \\
Adj. -sq & 26 & 26 & 26 & 0.3150 \\
Root MSE & 0.316 & 0.243 & 0.315 & 0.0757 \\
Log-likelihood & 0.287 & 0.243 & 0.315 & 31.057 \\
AIC & 0.0772 & 0.0757 & 0.0757 & -52.115 \\
BIC & 30.745 & 31.043 & 31.028 & -45.824 \\
\hline \hline
\end{tabular}

Table 6.5 Cross-sectional Estimations of Beta Convergence

Notes: Standard errors are shown in parentheses. Significance at the $1 \%(* * *), 5 \%(* *)$, and $10 \%(*)$ levels are indicated. Robust standard errors (except SEM and SAC) are used. W corresponds to the binary queen continuity matrix.

All models presented in Table 6.5 show that GVA per capita growth rate is negatively and significantly associated with the initial GVA per capita, indicating evidence for regional convergence. The estimated speed of convergence ranges from $1.7 \%$ to $2 \%$, which implies a 
half-life of 34 to 40 years. Our findings are in line with Barro and Sala-i-Martin's 2\% convergence rate, which is accepted as the iron law in the literature (Barro and Sala-i-Martin, 1991, 1992). Furthermore, we see that when we incorporate spatial variables into the crosssectional model, our estimations for convergence speed get closer to the iron law rate.

We also see that spatial models that take spatial dependence into account have better explanatory power than the basic OLS model and they achieve a better fit in terms of test statistics (R-sq, Log-likelihood, AIC, BIC). Nevertheless, none of the spatial dependence coefficients is significant. Moreover, given the p-values, model selection tests presented in Tables 6.6 and 6.7 do not indicate statistically significant results for any type of spatial dependence. In other words, cross sectional estimates reject the existence of spatial dependence among Turkish regions and indicate the OLS as the correct specification. On the other hand, we should be cautious while interpreting results of cross-sectional estimations for the existence of spatial dependence. As the number of observations in the cross-section regressions is only 26 , the models do not have much cross sectional variation to statistically show that the spatial dependence effect is different from zero. Thus, we use panel data analysis in order to take advantage of time series variation in data in addition to the cross sectional variation. One advantage of panel data over traditional cross-sectional approach is that it is not necessary to keep the steady-state constant because it can be implicitly estimated using fixed effects (Barro and Sala-i-Martin, 1995).

\begin{tabular}{lccc}
\hline \hline Tests & SAC vs OLS & SAC vs SAR & SAC vs SEM \\
\hline Likelihood Ratio (LR) test & & & \\
-Value & 0.625 & 0.029 & 0.059 \\
-P-value & 0.732 & 0.866 & 0.808 \\
Wald Test & & & \\
-Value & 0.63 & 0.03 & 0.06 \\
-P-value & 0.728 & 0.869 & 0.806 \\
\hline \hline
\end{tabular}

Table 6.6 Model Selection Tests of Cross-sectional Estimations: LR and Wald

\begin{tabular}{lccc}
\hline \hline Tests & MI/DF & Value & P-Value \\
\hline Lagrange Multiplier (LM) Test & & & \\
\hline LM (Lag/SAR) & 1 & 0.464 & 0.4955 \\
Robust LM (Lag/SAR) & 1 & 0.020 & 0.8884 \\
LM (Error) & 1 & 0.454 & 0.5003 \\
Robust LM (Error) & 1 & 0.009 & 0.9225 \\
LM (SARMA) & 2 & 0.474 & 0.7890 \\
\hline \hline
\end{tabular}

Table 6.7 Model Selection Tests of Cross-sectional Estimations: LM

Notes: LM tests are calculated based on Anselin $(1988,2001)$ and Anselin et al. (1996).

Table 6.8 reports the results of panel data estimations of the fixed effects and spatial maximum likelihood estimations. We basically replicated the estimations of the same econometric models used in the cross-sectional estimations in panel data settings. We prefer the fixed effects model to the random effects model because the results of Hausman's specification test (test statistic: 33.09, $p$-value: 0.000) rejects the null hypothesis where the preferred model is random effects. Moreover, we ran a joint test to see whether the dummies for all years are equal to 0 , and rejected the null hypothesis $(F$-statistics $=95.56, p$-value $=0000)$. As a result, we included both entity (region) and time fixed effects into our fixed effects estimations.

As in the case of the cross sectional estimates, panel data estimations also yield highly significant and negative coefficients for the initial income levels, confirming the existence of 
absolute beta convergence across Turkish regions. We observe a sharp difference in the convergence rate estimated by the two models: Our pooled OLS estimation yield a convergence speed of $3.2 \%$ per year, implying a half-life of 22 years. However, panel data estimations yield very high rates of convergence speed varying from $49.3 \%$ to 54.1 . In the literature, it is known that estimates of the speed of convergence from panel data with fixed effects tend to be much higher than the $2 \%$ per-year estimated from cross-sections or panels without fixed effects. Speeds of convergence ranging from 12 to 20 percent per year are not very uncommon in the literature (Barro and Sala-i-Martin, 1995).

\begin{tabular}{|c|c|c|c|c|c|}
\hline & Pooled OLS & $\begin{array}{c}\text { Fixed } \\
\text { Effects }(\mathbf{F E})\end{array}$ & SAR & SEM & SAC \\
\hline Dependent Variable: & \multicolumn{5}{|c|}{ GVA pc growth rate } \\
\hline $\ln ($ Initial GVA pc) & $\begin{array}{l}-0.0316^{* *} \\
(0.0155)\end{array}$ & $\begin{array}{l}-0.395 * * * \\
(0.0674)\end{array}$ & $\begin{array}{l}-0.389 * * * \\
(0.0634)\end{array}$ & $\begin{array}{l}-0.424 * * * \\
(0.0734)\end{array}$ & $\begin{array}{l}-0.418 * * * \\
(0.0696)\end{array}$ \\
\hline $\begin{array}{l}W^{*} G V A p c \\
\text { growth rate }\end{array}$ & & & $\begin{array}{c}0.154 * * \\
(0.0684)\end{array}$ & & $\begin{array}{l}-0.565^{* * *} \\
(0.146)\end{array}$ \\
\hline$W^{*}$ Error term & & & & $\begin{array}{l}0.243 * * * \\
(0.0640)\end{array}$ & $\begin{array}{l}0.645^{* * * *} \\
(0.085)\end{array}$ \\
\hline Constant & $\begin{array}{c}0.253 * * \\
(0.107) \\
\end{array}$ & $\begin{array}{l}2.735^{* * * *} \\
(0.454) \\
\end{array}$ & & & \\
\hline Region Effects & No & Yes & Yes & Yes & Yes \\
\hline Time Effects & No & Yes & Yes & Yes & Yes \\
\hline Convergence Speed & 0.032 & 0.503 & 0.493 & 0.552 & 0.541 \\
\hline Half-life Period (Years) & 22 & 1.4 & 1.4 & 1.3 & 1.3 \\
\hline Observations & 182 & 182 & 182 & 182 & 182 \\
\hline$R-s q$ & 0.027 & 0.832 & 0.245 & 0.239 & 0.194 \\
\hline Adj. $R-s q$ & 0.022 & 0.826 & & & \\
\hline Root MSE & 0.0786 & 0.328 & & & \\
\hline Log-likelihood & 205.558 & 368.015 & 369.428 & 371.134 & 374.748 \\
\hline$A I C$ & -407.116 & -722.030 & -732.856 & -736.268 & -741.496 \\
\hline$B I C$ & -400.708 & -699.602 & -723.244 & -726.656 & -728.680 \\
\hline
\end{tabular}

Table 6.8 Panel Estimations of Beta Convergence

Notes: Standard errors are shown in parentheses. Significance at the $1 \%(* * *), 5 \%(* *)$, and $10 \%(*)$ levels are indicated. Robust standard errors, clustered by region (except column 1), are used. W corresponds to the binary queen continuity matrix.

\begin{tabular}{lccc}
\hline \hline Tests & SAC vs FE & SAC vs SAR & SAC vs SEM \\
\hline Likelihood Ratio (LR) Test & & & \\
-Value & 13.466 & 10.640 & 7.227 \\
-P-value & 0.001 & 0.001 & 0.007 \\
\hline Wald Test & & & \\
-Value & 95.39 & 57.68 & 15.07 \\
-P-value & 0.000 & 0.000 & 0.000 \\
\hline \hline
\end{tabular}

Table 6.9 Model Selection Tests of Panel Estimations: LR and Wald

Our panel data estimates, unlike our cross-sectional estimates, yield highly significant results for spatial coefficients. Summary statistics in Table 6.8 show that inclusion of spatial parameters increases the explanatory power of our models and produces a better fit for our estimations. Model specification tests presented in Table 6.9 also indicate that both spatial lag 
and error dependences should be included into model estimations, thus the SAC model is suggested as the correct specification. In sum, our results underline the necessity of taking spatial dependence into account in convergence analysis and also point out that Turkish regions are affected by the developments in the neighboring regions.

\section{CONCLUSION}

We employed cross-sectional and panel estimations to test the existence of absolute beta convergence of GVA per capita in Turkish NUTS 2 regions for 2004-2011 period. All the models prove that GVA per capita growth rate is negatively associated with initial GVA per capita indicating evidence for regional economic convergence. Thus, our empirical findings support the beta convergence hypothesis such that poorer regions grow faster than the richer ones. This finding is in line with the prediction of the neo-classical growth model and international empirical evidence. The long-lasting regional policy priority of reducing regional development disparities was achieved in the period examined.

Relative reduction in the dispersion of GVA per capita across regions exhibits a sharp trend in 2008 and 2009 when Turkey felt the impact of the 2008 financial crisis. Inequality, however, increased in the pre-2006 period and in the post-2010 period when Turkey experienced high economic growth rates. These results are in line with the literature that crisis periods have asymmetrical effects at regional level. Regions with higher GVA per capita were hit more by the crisis leading to a faster convergence. As a result, inequality across regions decreases in the recession periods and increases in the economic expansion periods. Thus, regional economic convergence is proved to be countercyclical.

Panel models exhibit statistically significant results for the existence of spatial dependence. This finding implies that Turkish regions that are surrounded by regions with high growth rates are, on average, expected to grow faster. Thus, some regions grow faster just because they have "better" neighbors. This finding proves that spatial econometric techniques should always be used when analyzing territorial units in order to better understand the regional growth dynamics. In the case of Turkey, this finding shows that economic division between Western and Eastern regions has a self-reinforcing nature. Western regions grow faster and help their neighboring regions to do the same, creating a larger region of economic growth, while Eastern regions lack this collective regional dynamic. On the policy side, the lesson is that regional policies should take this duality into account if the vicious cycle in the Eastern regions is targeted to be broken, or the virtuous cycle in the Western region is addressed to be exploited.

\section{REFERENCES}

Abramovitz, M. (1986). Catching Up, Forging Ahead, and Falling Behind. Journal of Economic History, 46 (2), 385-406.

Aldan, A. and E. Gaygisiz (2006). Convergence Across Provinces of Turkey: A Spatial. Analysis. Research and Monetary Policy Department Working Paper No. 06/09. Central Bank of the Republic of Turkey, Ankara.

Anselin, L., A.K. Bera, R. Florax and M.J. Yoon (1996). Simple Diagnostic Tests for Spatial Dependence. Regional Science and Urban Economics, 26 (1), 77-104. 
Anselin, L. (1988). Spatial Econometrics: Methods and Models. Dordrecht: Kluwer Academic Publishers.

Anselin, L. (1995). Local Indicators of Spatial Association. Geographical Analysis, 27 (2), 93115.

Anselin, L. (2001). Rao's Score Test in Spatial Econometrics. Journal of Statistical Planning and Inference, 97, 113-139.

Atalik, G. (1990). Some Effects of Regional Differentiation on Integration in the European Community. Papers in Regional Science Association, 69, 11-19.

Atkinson, A.B. (1970). On the Measurement of Inequality. Journal of Economic Theory, 2 (3), 244-263.

Atkinson, A.B. (1975). On the Measurement of Inequality. Oxford: Oxford University Press.

Atkinson, A.B. (1983). The Economics of Inequality. Second edition, Oxford: Clarendon Press.

Banerjee, A. and P.K. Kuri (2015). Development Disparities in India: An Enquiry into Convergence. New Delhi: Springer India.

Barro, R.J. and X. Sala-i-Martin (1990). Economic Growth and Convergence across the United States. National Bureau of Economic Research Working Paper No. 3419.

Barro, R.J. and X. Sala-i-Martin (1991). Convergence Across States and Regions. Brookings Papers on Economic Activity, 22 (1). 107-82.

Barro, R.J. and X. Sala-i-Martin (1992). Convergence. Journal of Political Economy, 100 (2). 223-251.

Barro, R.J. and X. Sala-i-Martin (1995). Economic Growth. New York: McGraw-Hill.

Barro, R. (1991). Economic Growth in A Cross Section of Countries. Quarterly Journal of Economics, 106, 407-443.

Baumol, W. (1986). Productivity Growth, Convergence and Welfare: What Do the Long Run Data Show? American Economic Review, 76 (5), 1072-1085.

Berber, M., R. Yamak and S. Artan (2000). Türkiye'de Yakınlaşma Hipotezinin Bölgeler Bazında Geçerliliği Üzerine Ampirik Bir Çalışma: 1975-1997. In 9. Ulusal Bolge Bilimi Kongresi-Bildiriler Kitabı. Trabzon, 51-59.

Borsi, M.T. and N. Metiu (2015). The Evolution of Economic Convergence in the European Union. Empirical Economics, 48(2), 657-681.

Cashin, P. (1995). Economic Growth and Convergence Across the Seven Colonies of Australasia: 1861-1991. The Economic Record, 71 (213), 132-144. 
Celbis, M.G. and D. Crombrugghe (2014). Can internet infrastructure help reduce regional disparities? Evidence from Turkey. UNU-MERIT Working Paper Series \#2014-078, Maastricht, United Nations University.

Celebioğlu, F. and S. Dall'erba (2010). Spatial Disparities across the Regions of Turkey: An Exploratory Spatial Data Analysis. The Annals of Regional Science, 45 (2), 379-400.

Chatterji, M. (1992). Convergence Clubs and Endogenous Growth. Oxford Review of Economic Policy, 8 (4). 57-69.

Cliff, A. D. and J.K. Ord (1975). The choice of a test for spatial autocorrelation. In Display and Analysis of Spatial Data, ed. J.C. Davies and M.J. McCullagh. London: John Wiley and Sons, 54-77.

Coulombe, S. and F.C. Lee (1995). Convergence across Canadian provinces 1961 to 1991. Canadian Journal of Economics, 28 (4), 886-898.

Dawkins, C.J. (2003). Regional Development Theory: Conceptual Foundations, Classic Works, and Recent Developments. Journal of Planning Literature, 18 (2), 131-172.

Fuente, A. (2002). Regional Convergence in Spain: 1965-95. CEPR Discussion Paper No. 3137.

Doğruel, F. and A.S. Doğruel (2003). Türkiye'de Bölgesel Gelir Farklılıkları ve Büyüme. In Iktisat Üzerine Yazılar I: Küresel Düzen: Birikim, Devlet ve Sinıflar (Korkut Boratav'a Armă̆an), ed. A.H. Köse, F. Şenses and E. Yeldan. İstanbul: İletişim, 287-318.

Eckey, H.F., R. Kosfeld and M. Türck (2007). Regional Convergence in Germany: A Geographically Weighted Regression Approach. Spatial Economic Analysis, 2 (1), 45-64.

Elhorst, P.J. (2014). Spatial Econometrics: From Cross-sectional Data to Spatial Panels. London: Springer.

Erlat, H. (2005). Türkiye'de Bölgesel Yakınsama Sorununa Zaman Dizisi Yaklaşımı. In Bölgesel Gelişme Stratejileri ve Akdeniz Ekonomisi, Turkish Economic Association, ed. H. Erlat. Ankara, 251-276.

Filiztekin, A. (1998). Convergence Across Industries and Provinces in Turkey? Koc University Working Paper No.1998/08. Koc University, İstanbul.

Galor, O. (1996). Convergence? Inferences from Theoretical Models. Economic Journal, 106 (437), 1056-1069.

Gezici, F. and G.J.D. Hewings (2002). Spatial Analysis of Regional Inequalities in Turkey. The Real Economics Applications Laboratory Discussion Paper REAL 02-T-11. Urbana: The Real Economics Applications Laboratory.

Gezici, F. and G.J.D. Hewings (2004). Regional Convergence and the Economic Performance of Peripheral Areas in Turkey. Review of Urban and Regional Development Studies, 16 (2),113-132. 
Griffith, D.A. (2003). Spatial Autocorrelation and Spatial Filtering: Gaining Understanding Through Theory and Scientific Visualization. Berlin: Springer-Verlang.

Gripaios, P., P. Bishop and S. Keast (2000). Differences in GDP Per Head in GB Counties: Some Suggested Explanations. Applied Economics, 32 (9), 1161-1167.

Habibullah, M.S., A.M. Dayang-Fizzah, V.K.S. Liew and K.P. Lim (2008). Testing Nonlinear Convergence in Malaysia 1965-2003. MPRA Paper No. 12110.

Haughton, J. and S.R. Khandker (2009). Handbook on Poverty and Inequality. The World Bank, Washington, DC.

Hofer, H. and A. Wörgötter (1997). Regional per capita Income Convergence in Austria. Regional Studies, 31 (1), 1-12.

Kakwani, N.C. (1980). Income inequality and poverty: methods of estimation and policy applications. New York: Oxford University Press.

Kakwani, N. (1988). Income inequality, welfare and poverty in a developing economy with applications to Sri Lanka. Social Choice and Welfare, 5 (2-3), 199-222.

Kakwani, N. (1990). Large sample distribution of several inequality measures with application to Cote d'Ivoire. Living standards measurement study (LSMS) working paper No. LSM 61. Washington DC: The World Bank.

Kangasharju, A. (1998). Beta Convergence in Finland: Regional Differences in Speed of Convergence. Applied Economics, 30 (5), 679-687.

Karaca, O. (2004). Türkiye'de Bölgeler Arası Gelir Farklılıkları: Yakınsama Var mı? Discussion Paper No. 2004/7. Ankara: Turkish Economic Association.

Krugman, P. (1991). Geography and Trade. London: MIT Press.

Lesage, J. and R.K. Pace (2009). Introduction to Spatial Econometrics. Boca Raton: CRC Press, Taylor \& Francis Group.

Litchfield, J.A. (1999). Inequality: Methods and Tools. The World Bank Discussion paper, Washington DC.

Lucas, R.E.Jr. (1988). On the Mechanics of Economic Development. Journal of Monetary Economics, 22, 3-42.

Mauro, L. and E. Podrecca (1994). The Case of Italian Regions: Convergence or Dualism? Economic Notes, 23 (3), 447-472.

Maza, A., M. Hierro and J. Villaverde (2012). Income distribution dynamics across European regions: Re-examining the role of space. Economic Modelling, 29 (6), 2632-2640. 
Monfort, P. (2008). Convergence of EU regions Measures and evolution. European Commission Directorate General for Regional Policy Working Paper 01/2008.

Michelis, L., A. Papadopoulos and G. Papaniko (2004). Regional Convergence in Greece in the 1980s: An Econometric Investigation. Applied Economics, 36 (8), 881-888.

OECD (2013). Regions at a Glance. Paris: OECD Publishing.

Öztürk L. (2013). Does Turkey Converging to the European Union? A Time Series Analysis, 1950-2008. Ege Academic Review, 13 (4), 527-538.

Persson, J. (1997). Convergence Across the Swedish Counties 1911-1993. European Economic Review, 41, 1835-1852.

Rey, S.J. and B.D. Montouri (1999). U.S. Regional Income Convergence: A Spatial Econometric Perspective. Regional Studies, 33, 143-156.

Romer, P. M. (1986). Increasing Returns and Long Run Growth. Journal of Political Economy, 94 (5), 1002-1037.

Sala-i-Martin, X. (1996). Regional Cohesion: Evidence and Theories of Regional Growth and Convergence. European Economic Review, 40 (6), 1325- 1352.

Serra, M.I., M.F. Pazmino, G. Lindow, B. Sutton and G. Ramirez (2006). Regional Convergence in Latin America. IMF Working Paper Series 06/125.

Shahateet, M.I. (2006). How Serious Regional Economic Inequality in Jordan? Evidence from Two National Household Surveys. American Journal of Applied Sciences, 3 (2), 17351744.

Shankar, R. and A. Shah (2003). Bridging the Economic Divide within Nations: A Scorecard on the Performance of Regional Development Policies in Reducing Regional Income Disparities. World Development, 31 (8), 1421-1441.

Siriopoulos, C. and D. Asteriou (1998). Testing for Convergence Across the Greek Regions. Regional Studies, 32 (6), 537-546.

Solow, R.M. (1956). A Contribution to the Theory of Economic Growth. The Quarterly Journal of Economics, 70 (1), 65-94.

Swan, T. (1956). Economic Growth and Capital Accumulation. Economic Record, 32, 334-61.

Tansel, A. and N.D. Güngör (1998). Economic Growth and Convergence: An Application to the Provinces of Turkey 1975-1995. ERC Working Paper No. 98/9. Ankara: Middle East Technical University.

Theil, H. (1967). Economics and Information Theory. Amsterdam: North-Holland. 
TURKSTAT (2014). Gayri Safi Katma Değer, Bölgesel Sonuçlar, 2004-2011. TURKSTAT Website. https://biruni.tuik.gov.tr/yayin/views/visitorPages/index.zul (accessed September 15, 2016).

Vidyattama, Y. (2013). Regional Convergence and the Role of the Neighbourhood Effect in Decentralised Indonesia. Bulletin of Indonesian Economic Studies, 49 (2), 193-211.

Wahiba, N.F. (2014). Regional Development and Inequality of Income Distribution. International Journal of Academic Research in Economics and Management Sciences, 3 (2).

Williamson, J. G. (1965). Regional Inequality and the Process of National Development: A Description of the Patterns. Economic Development and Cultural Change, 13 (4), 1-84.

Yildırım, J. and N. Öcal (2006). Income Inequality and Economic Convergence in Turkey. Transition Studies Review, Springer-Verlag, 13 (3), 559-568.

Yıldırım, J., N. Öcal and S. Özyıldırım (2009). Income Inequality and Economic Convergence in Turkey: A Spatial Effect Analysis. International Regional Science Review, 32 (2), 221254. 